University of Tennessee Health Science Center

UTHSC Digital Commons

Faculty Presentations

College of Graduate Health Sciences

Spring 5-21-2020

\title{
Black Women Survive Breast Cancer with Community-Based Care
}

Shelley I. White-Means

University of Tennessee Health Science Center

Jill Dapremont

University of Memphis

Barbara D. Davis

University of Memphis

Tronlyn Thompson

Howard University

Follow this and additional works at: https://dc.uthsc.edu/cghs_presentations

Part of the Community Health and Preventive Medicine Commons, Health Services Administration Commons, Health Services Research Commons, Neoplasms Commons, and the Women's Health Commons

\section{Recommended Citation}

White-Means, Shelley I.; Dapremont, Jill; Thompson, Tronlyn and Davis, Barbara D., "Black Women Survive Breast Cancer with Community-Based Care" (2020). Xavier Health Disparities Conference, Xavier University, New Orleans, LA, USA, May 25-27, 2020. Faculty Presentations. 1. Due to Covid-19 related conference cancellation, this peer-reviewed poster was disseminated on $05 / 21 / 2020$ to https://dc.uthsc.edu/cghs_presentations/1. http://dx.doi.org/10.21007/cghs.fpres.2020.0001

This Poster is brought to you for free and open access by the College of Graduate Health Sciences at UTHSC Digital Commons. It has been accepted for inclusion in Faculty Presentations by an authorized administrator of UTHSC Digital Commons. For more information, please contact jwelch30@uthsc.edu. 


\section{Background}

* Community-based breast cancer support agencies who address nonmedical, social determinants of health needs that serve as barriers to maximizing breast health outcomes may play a vital role in mitigating breast cancer mortality.

They share a common emphasis on addressing social, economic, and psychological needs of breast cancer survivors and those at risk of breast cancer.

Services provided by these agencies complement services provided by primary care and oncological treatment providers as well as family caregivers.

Community-based breast cancer support agencies include patient navigator (generally affiliated with hospitals or comprehensive clinics), local breast an cervical cancer and early detection programs (funded by CDC), and breast cancer support groups (sometimes referred to as supportive-expressive group therapy).

Community-based breast cancer support agencies have a close-up view of circumstances and decision-making among women at risk of and surviving breast cancer, and a close view of primary care, surgical, and insurance environments impacting these women.

\section{Objectives}

This paper is third in a series of papers exploring why the rate of breast cancer mortality is two times higher for African American women than white women in Memphis. It

* seeks insights regarding racial disparities in breast health outcomes in Memphis from key service providers for screening and breast cancer survivorship, i.e., community-based breast cancer support agencies.

- reports how support agency providers perceive the challenges that African American women face in maintaining their breast health as well as potential solutions.

\section{Methods}

Qualitative, descriptive study of 5 of 6 community-based breast cancer support agencies serving African-American patients in Memphis, TN

$>$ Convenience Sampling of representatives from three breast cancer support groups, a patient navigator organization, and a Tennessee Breast and Cervical Cancer Program.

- 9 question, semi-structured interview guide with sub-questions

- 90 minute face-to-face interview and one follow-up telephone interview lasting 2 hours, conducted February, 2018

Transcriptions were analyzed question by question using manual open coding with each interview. Themes and subthemes were established using thematic analysis and a deductive a priori template of codes, based on the interview questions.

$>$ Data management was performed through development of suitable classification or coding schemes by breaking down the data into discrete parts closely examined, paralleled for similarities and differences, and compared repeatedly until saturation was determined

\begin{tabular}{|l|l|}
\multicolumn{1}{|c|}{ Results } \\
\hline \multicolumn{2}{|c|}{ Demographics } \\
\hline Number of Participants & 5 \\
\hline Gender & Female \\
\hline Age Range & $54-68$ \\
\hline Ethnicity & African American \\
\hline Educational Attainment & I Associates Degree, I BS, 2 MA, I EdD \\
\hline Collective Years at Agencies & 100 \\
\hline
\end{tabular}

Four Main Themes emerged from the providers interviews: 1) Barriers to Use of Services

Women may not access services due to fear, procrastination, desire for a second opinion, unwillingness to accept the diagnosis, or lack of transportation.

...but you can't just tell someone 'well you need to go.' What you do is you need to be there with them...even when the doctor said there isn't anything we can do about it, and even when she was dying..., it takes an individual not to just say a few things and get them

Cost of medications may be a barrier, even for women with health insurance coverage.

"People they get these drugs and they're $\$ 900$ a pill, you know, what do you do with that?" Access may also be limited because of where certain racial/ethnic and socioeconomic groups live.

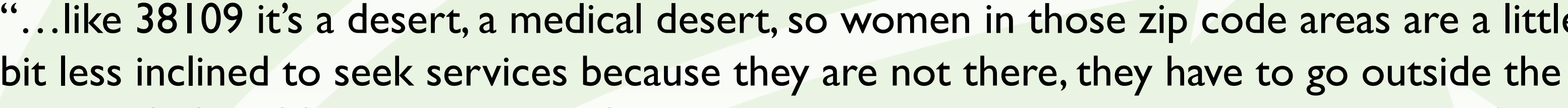
radius of 10 to 20 miles outside of your neighborhood or zip code to get services, it's a barrier for them."

\section{2) Education}

Because women are visual, breast demonstrations and models that reflect the various stages of the cancer are most helpful for their understanding of the impacts of breast cancer and what the outcome may look like. While demonstrations are provided, a demonstration is a good time to "dispel some of the myths and fears they have."

"We do a Hats Off.llike a skit where you have humor...it gets people to pay attention" "[Support group leader] has someone to come in and to educate on Saturdays so we are
always doing something and learning something."

\section{3) Health System Support}

\section{"Mobile units have too many barriers or stipulations to receive the service that makes it} ineffective."

Sometimes the doctor is the barrier to effective care and breast cancer survival.

“...they don't have good bedside manners, and then they put even more fear in her when she comes in. Often times they'll talk and say things the woman don't understand and so that appointment to help you understand what they're talking about."

Sometimes, the way care is managed in the physician's office may become a barrier. This is a health system concern.

"If a lady doesn't have a good primary care doctor, it might be months before the person months; may not have a proactive person at the office."

\section{Results}

\section{4) Emotional Support}

Back in the day, grandmothers were a barrier to treatment. They would say, "oh honey...you're fine, if you're not hurting or anything you're fine."

Sometimes, the appropriate family support is not there because the women don't want their family members to know that they have cancer. Some family members may distance themselves if a person has a lot of financial needs all the time, and those family members need to use their limited resources to take care of themselves.

Receiving emotional support from a significant other affects decisions: "...men in their lives may leave them; husband became mentally abusive once she got realize that women may not have to have a mastectomy, may only have a scar, may not
need to have chemo, may live $40-50$ years longer."

\section{Conclusions}

- Community-based breast cancer support agencies, who focus on socia determinants of health play a critical role as connectors for women with s for women with breast cancer who live in medically underserved areas and must find their way within a fragmented medical system.

- Being an insider vs. an outsider to support agency programs can make a difference in whether or not one receives encouragement, up-to-date information about breast cancer and resources, scheduling support, and financial supplements for screening and treatment. Support agencies intervene to curb barriers to maintaining breast health.

* By identifying themselves as the medical home and implementing less stringent poverty guidelines, support agencies increase access to the use of mobile mammography services. * Collaborate with hospitals to facilitate provision of midnight mammography services. loqer ible to work ind hation limited finansportation needs for survivors who are no treatment.

* For those with limited health literacy, they assist with health insurance enrollment. * Provide one-on-one personal support that may counter a lack of family support due to cultural norms that contrast traditional medicine norms

specifically for the particular issues and challenges of the breast that is designed

\section{Recommendations}

- Support agencies noted that one unique barrier that African-American women who live in underserved areas of Memphis face in maintaining breast health is poor physician's office management; in fragmented health care systems, information and patients can be lost to follow-up. New strategies in this area are needed.

- Despite their vital role in reducing breast cancer mortality, communitybased breast cancer support agencies are underfunded. They are largely volunteer workers with their feet-on-the-ground who can easily identify needs, but face great difficulty in identifying adequate financial resources in meeting those needs. There is a clear and substantial return on investment and cost savings opportunity by directing more resources to programs of community-based breast cancer support agencies.

This research was funded by the Tennessee Department of Health, grant number A7- 